\title{
Recovery of lubricant base oils using ionic liquid processes
}

Sue M Grimes* and Feyisetan Thompson

Department of Civil and Environmental Engineering, Imperial College London SW7 2AZ

*Corresponding Author: Professor Sue Grimes, Department of Civil and Environmental Engineering, Imperial College London SW7 2AZ; Tel: 02075945966 Email: s.grimes@imperial.ac.uk

\begin{abstract}
Two novel low-temperature ionic liquid processes are developed for the recovery of base oils from waste lubricant oils. One uses 3-(triethoxysilyl)-propylammonium-3-(triethoxysilyl)-propyl carbamate (TESAC), in which the waste lubricant base oil is insoluble, and the other uses trihexyltetradecylphosphonium chloride $\left(\mathrm{P}_{6}, 6,6,14 \mathrm{Cl}\right)$ in which the base oil is soluble. In the TESA/TESAC process waste oil components, including the base oil, are dissolved in the solvent 3-aminopropyl-triethoxysilane (TESA) which is converted, in situ, with carbon dioxide to TESAC, recovering the base oil as an insoluble layer. In the $\mathrm{P}_{6,6,6,14} \mathrm{Cl}$ process the base oil is separated from most additives as a solution in the ionic liquid from which it can be extracted with methanol. The recovered oils from both processes have properties consistent with lubricant oils in commercial use and the ionic liquids can be recovered for recycle minimising reagent use and providing a route to closed-loop base oil recovery and recycle.
\end{abstract}

Keywords: Waste management and disposal; Recycling and reuse of materials; Environment; 


\section{Introduction}

Lubricating oils are mixtures of hydrocarbon base oils $(71.5-96.2 \mathrm{wt} \%)$ with additives that are included to meet the requirements of specific lubricants (Mohammed et al., 2013). In service, the oils undergo oxidation in the presence of high engine temperatures that lead to free radical autocatalysis to give a complex mixture of products that can cause corrosion and reduce the effectiveness of the lubricant. Most of the estimated 40 million tonnes of lubricant oils produced annually worldwide end up as waste lubricant oils (Lea-Langton et al., 2010) that are classified in the EU list (European Commission, 2014), as hazardous materials. The main methods used in managing waste lubricating oils are recovery for reuse and recycle (Jafari \& Hassanpour, 2015), hydrocracking to produce fuels (Tripathi et al., 2015; Khowatimy et al., 2014), and incineration with energy recovery (Fuentes et al., 2007). While hydrocracking and incineration can give rise to only one second use for the waste oil, recovery for recycle provides the opportunity to achieve multiple reuse stages for recycled oils and should, with the use of suitable technologies, be the preferred management option. In 2010 the estimated annual consumption of lubricating oil in 15 EU countries (Pawlak et al., 2010; Hsu and Liu, 2011) was about 5Mt with only 1.7Mt being recovered for reuse.

The steps involved in the re-refining generally involve pre-cleaning, extraction and separation, and hydro-finishing and the viability of the processes is influenced by factors such as process costs, market prices, regulatory frameworks and market acceptance of the recyclates in addition to environmental issues such as the use of volatile solvents and the production of solid wastes that lead to disposal problems. Many types of re-refining separation stages (Jafari \& Hassanpour, 2015; Hsu et al., 2010; Kanokkantapong et al., 2009) have been established for the recovery of 
waste lubricant oils all of which involve the removal of the high-temperature oxidation products and friction products resulting in recovered oils suitable for reuse. The processes include: (i) adsorption processes such as acid-clay treatment (Emam, and Shoaib 2012), which can be combined with distillation but which are generally regarded as less efficient and not environmentally sound; (ii) processes involving volatile organic solvents including solvent extraction (Lukic et al., 2006, Hamad et al., 2005; Elbashir et al., 2002), solvent extraction with adsorption (Mohammed et al., 2013; Kamal \& Khan, 2009), and solvent flocculation (Martins, 1997) and (iii) supercritical fluid extraction (Liu et al., 2005). Most of the standard processes involve steps that make use of high temperatures, adsorbents that have to be disposed of as hazardous materials or volatile organic solvents all of which adversely affect their economic and/or environmental suitability. Ionic liquids are, however, solvents that are non-volatile and that have the potential to be used at room temperature as replacements for volatile organic solvents in the separation step of re-refinement processes. Ionic liquids (ILs) (Welton, 1999; Wilkes, 2002; Rogers \& Voth, 2007) are charged organic salts that are either liquid at room temperature (RTILs), or are low melting point $\left(<100{ }^{\circ} \mathrm{C}\right)$ solids. They have a unique range of properties including zero or minimal vapour pressure which makes them non-volatile, high solvation capacity which makes them useful solvents, wide temperature ranges of liquid phase stability, and very low flammability that make them ideal for a wide variety of applications including: use as solvents to dissolve hydrocarbons (Pereiro \& Rodriguez, 2010), use in separation and extraction processes (Lateef et al., 2008, 2009a, 2009b, 2012) and as replacements for volatile organic solvents (Cull et al., 2000). 
We now report on alternative low temperature re-refining processes for waste lubricant oils that are based on the solubilities of the waste oil components in ionic liquids.

\section{Materials \& Methods}

The ability of ionic liquids to dissolve components of waste lubricant oils was tested using a wide variety of ionic liquids and the results are reported for the following representative types: (i) polar ionic liquids: 1-butyl-3-methylimidazolium chloride [BMIMCl], 1-sulphonyl-3methylimidazoliumhydrogensulphate $\left[\mathrm{SMIMHSO}_{4}\right]$, betaine bis(trifluoromethylsulfonyl)imide [HBetNTf 2 ], 1-hexyl-3-methylimidazolium bromide [HMIMBr], and (ii) non-polar ionic liquids:

3-(triethoxysilyl)-propylammonium-3-(triethoxysilyl)-propyl carbamate [TESAC] and trihexyltetradecylphosphonium chloride $\left[\mathrm{P}_{6,6,6,14} \mathrm{Cl}\right]$. The ionic liquids $\mathrm{BMIMCl} \mathrm{SMIMHSO}_{4}$, and HMIMBr were synthesised by microwave-assisted methods, previously described (Lateef et al., 2009a, 2009b, 2012), while HBetNTf 2 was prepared by metathesis (Nockemann et al., 2006). TESAC was prepared by bubbling carbon dioxide through the solvent 3-aminopropyltriethoxysilane (TESA) (10g), until the exothermic reaction between the reactants ceased, giving a clear viscous ionic liquid - TESAC. This ionic liquid is stable below $46^{\circ} \mathrm{C}$ whilst, above this temperature, the reverse reaction occurs with loss of $\mathrm{CO}_{2}$ to reform TESA - a reversible reaction that has been used in carbon capture energy applications (Blasucci et al., 2009). The ionic liquid, $\mathrm{P}_{6,6,6,14} \mathrm{Cl}$, was purchased from Sigma Aldrich.

\subsection{Solubility of waste oil components in ionic liquids}

The solubilities of waste oil components and, particularly of the base oils and the additives crucial to the performance of the lubricant (antioxidants, friction modifiers, anti-wear agents, anti-foaming 
agents, and dispersants), in these ionic liquids, were determined to ascertain whether differences in their solubilities in the ILs can be exploited in the recovery of value from waste oils. The lubricant components used in the solubility tests are listed in Table 1.

\begin{tabular}{|c|c|c|}
\hline \multirow{2}{*}{ Category } & Component & Supplier \\
\hline Anti-wear and secondary anti-oxidant & Zinc dialkyl dithiophosphate (ZDDP) & ZPlus $^{\mathrm{TM}}$ USA \\
\hline Anti-foaming agent & Polydimethyl siloxane (PDMS) & Sigma Aldrich \\
\hline Anti-oxidant & 2,6 -di-tert-butyl-4-methylphenol & Sigma Aldrich \\
\hline Dispersant/emulsifier & (BHT) & Sigma Aldrich \\
\hline Friction Modifier & Moly(styrene-co-maleic acid) (PMS) & Sigma Aldrich \\
\hline Base oil & SN150 & Oando, Nigeria \\
\hline Waste lubricant oil & GM10W-40 & Local garage, UK \\
\hline
\end{tabular}

Table 1 - Lubricant oil components used in solubility testing

Except for TESAC, the method used in determining the solubilities of the lubricant oil components involved mixing each component separately with the ILs at room temperature $\left(22^{\circ} \mathrm{C}\right)$ and $80{ }^{\circ} \mathrm{C}$, separately. Each component $(50 \mathrm{mg})$ was mixed with the IL $(2 \mathrm{~g})$ in a glass vessel in a temperaturecontrolled water bath and the mixture stirred for 30-45 minutes at each temperature to determine the relative solubility of the component by measuring the weight of undissolved material. The relative solubilities of the oil components in TESAC (and its precursor, TESA) were determined using the same procedure but only at room temperature because of the thermal instability of TESAC at higher temperatures (Blasucci et al., 2009). All measurements were carried out in triplicate. The results of the relative solubilities of the base oils and additives in the ILs and in the solvent TESA are in Table 2. 


\begin{tabular}{|c|c|c|c|c|c|c|c|c|c|c|c|c|}
\hline \multirow[t]{2}{*}{ Components } & \multicolumn{2}{|c|}{ BMIMCI } & \multicolumn{2}{|c|}{ HBetNTf $_{2}$} & \multicolumn{2}{|c|}{ HMIMBr } & \multicolumn{2}{|c|}{$\mathrm{SMIMHSO}_{4}$} & \multicolumn{2}{|c|}{$\mathrm{P}_{6,6,6,14} \mathrm{Cl}$} & \multirow{2}{*}{$\begin{array}{c}\text { TESAC } \\
22^{\circ} \mathrm{C}\end{array}$} & \multirow{2}{*}{$\begin{array}{l}\text { TESA } \\
22^{\circ} \mathrm{C}\end{array}$} \\
\hline & $22^{\circ} \mathrm{C}$ & $80^{\circ} \mathrm{C}$ & $22^{\circ} \mathrm{C}$ & $80^{\circ} \mathrm{C}$ & $22^{\circ} \mathrm{C}$ & $80^{\circ} \mathrm{C}$ & $22^{\circ} \mathrm{C}$ & $80^{\circ} \mathrm{C}$ & $22^{\circ} \mathrm{C}$ & $80^{\circ} \mathrm{C}$ & & \\
\hline SN150 & i & i & i & $\mathbf{i}$ & $\mathbf{i}$ & i & i & i & $\mathbf{s}$ & $\mathbf{s}$ & i & $\mathbf{s}$ \\
\hline $\begin{array}{c}\text { Zinc dialkyl } \\
\text { dithiophosphate(ZDDP) }\end{array}$ & $\mathbf{i}$ & $\mathbf{i}$ & $\mathbf{i}$ & $\mathbf{i}$ & i & $\mathbf{i}$ & $\mathbf{i}$ & $\mathbf{i}$ & $\mathbf{s}$ & $\mathbf{s}$ & $\mathbf{S}$ & $\mathbf{s}$ \\
\hline $\begin{array}{c}\text { Molybdenum disulphide } \\
\left(\mathrm{MoS}_{2}\right)\end{array}$ & i & $\mathbf{i}$ & $\mathbf{i}$ & $\mathbf{i}$ & $\mathbf{i}$ & $\mathbf{i}$ & $\mathbf{i}$ & i & i & $\mathbf{i}$ & $\mathbf{s}$ & $\mathbf{s}$ \\
\hline $\begin{array}{c}\text { Polydimethyl siloxane } \\
\text { (PDMS) }\end{array}$ & $\mathbf{i}$ & $\mathbf{i}$ & $\mathbf{i}$ & $\mathbf{i}$ & $\mathbf{i}$ & $\mathbf{i}$ & i & i & $\mathbf{i}$ & $\mathbf{s}$ & $\mathbf{S}$ & $\mathbf{s}$ \\
\hline $\begin{array}{l}\text { 2,6-di-tert-butyl-4- } \\
\text { methylphenol (BHT) }\end{array}$ & $\mathbf{i}$ & $\mathbf{S}$ & $\mathbf{i}$ & i & $\mathbf{i}$ & $\mathbf{i}$ & $\mathbf{i}$ & $\mathbf{S}$ & $\mathbf{i}$ & $\mathbf{s}$ & $\mathbf{i}$ & $\mathbf{s}$ \\
\hline $\begin{array}{c}\text { Poly(styrene-co-maleic } \\
\text { acid) (PMS) }\end{array}$ & $\mathbf{i}$ & $\mathbf{S}$ & $\mathbf{i}$ & i & $\mathbf{i}$ & $\mathbf{i}$ & i & i & i & $\mathbf{i}$ & $\mathbf{S}$ & $\mathbf{s}$ \\
\hline
\end{tabular}

i - Insoluble; s-Soluble

Table 2 Relative solubilities of waste lubricant oil components in ILs at room-temperature $\left(22^{\circ} \mathrm{C}\right)$ and at $80^{\circ} \mathrm{C}$

\subsection{Ionic liquid methodology for the recovery of base oils from waste lubricant oils}

On the basis of the relative solubility data in Table 2 , TESAC and $\mathrm{P}_{6,6,6,14} \mathrm{Cl}$ were selected as potential solvents for the recovery of the base oil from waste lubricant oils in two alternative processes. In one process, using TESAC, the base oil is insoluble in the IL in which most of the other components are soluble while in the other process, using $\mathrm{P}_{6,6,6,14} \mathrm{Cl}$, the base oil is soluble in the IL in which the other components are insoluble.

\subsubsection{The TESA/TESAC base oil recovery process}

This process relies on the fact that the base oil (SN150), although soluble in TESA, is insoluble in TESAC while the other major components are soluble in both TESAC and in the precursor solvent 
TESA. The effectiveness of the process was tested using four systems: (i) the pure base oil; (ii) a simple simulated waste lubricant oil; (iii) a mixed simulated waste lubricant oil; and (iv) a real waste lubricant oil.

Pure base oil: In studies using the pure base oil, SN150 (5g), was dissolved in TESA (0.05 mol, $11 \mathrm{~g}$ ) at room temperature and $\mathrm{CO}_{2}$ was bubbled through the solution at $3.7 \mathrm{~cm}^{3} / \mathrm{min}$ for 15 minutes until the exothermic reaction was complete and a viscous mixture formed leading to the production of TESAC. The initial homogeneous one-phase mixture, formed by TESA and the base oil, was allowed to separate into two distinct layers, with the base oil in the upper layer and the IL, TESAC, in the lower layer. The attenuated total reflectance-Fourier transform infrared spectroscopy (ATRFTIR) spectrum of the upper layer was recorded and compared with that of the reference base oil.

Simple simulated waste lubricant oil system: A model waste oil was prepared by heating the pure base oil in a glass vessel at $120^{\circ} \mathrm{C}$ for $50 \mathrm{~h}$ in air to oxidize the hydrocarbons to simulate degradation in an engine environment and used in studies of simulated waste lubricant oil systems. The simple simulated waste lubricant oil system studied contained only one oil additive, the antifoaming agent polydimethylsiloxane (PDMS) $(1.8 \mathrm{~g})$ in the model waste oil $(5 \mathrm{~g})$ in a homogeneous mix that was added to TESA $(5 \mathrm{~g})$ at room temperature. The TESA was then converted to TESAC, by the same process used in the studies of the pure base oil, to recover the base oil. The upper layer, containing the recovered base oil was separated from the lower TESAC/PDMS layer by centrifuging the mixture at $8000 \mathrm{rpm}$ for $20 \mathrm{~min}$. The upper layer was washed with methanol $(20 \mathrm{~mL})$ to remove any traces of PDMS and IL and the ATR-FTIR spectrum of the recovered product compared with that of the reference base oil. 
Mixed simulated waste lubricant oil system: A mixed simulated waste lubricant oil system was prepared from the oxidised model waste oil ( $8 \mathrm{~g}$ ), by adding the following additives: $\mathrm{MoS}_{2}[0.33 \mathrm{~g}]$, PDMS [0.33g], BHT [1g], ZDDP [0.33g] and PMS [0.33g]) to give a homogeneous mixture that was added to TESA ( $10 \mathrm{~g})$ at room temperature. The TESA was then converted to TESAC by the same process used in the studies of the pure base oil to recover the base oil. The upper layer, containing the recovered base oil was separated from the lower TESAC/additives layer by centrifuging the mixture at $8000 \mathrm{rpm}$ for $30 \mathrm{~min}$. The upper layer was washed with methanol to remove any traces of additives and IL, and the ATR-FTIR spectrum of the recovered product compared with that of the reference base oil.

Real waste lubricant oil system: The recovery of base oil from a real waste lubricant oil system was studied using waste GM10W-40, a multi-grade semi-synthetic lubricant oil obtained from a local garage in the UK. The waste lubricant oil was filtered to remove sediments and a 1:1 mixture of TESA $(10 \mathrm{~g})$ and the filtered waste lubricant oil $(10 \mathrm{~g})$ was placed in a flask and $\mathrm{CO}_{2}$ bubbled through at the rate of $3.7 \mathrm{~cm}^{3} / \mathrm{min}$, for 15 minutes at room temperature to produce a mixture of TESAC and the waste lubricant oil. The resulting mixture was centrifuged at $8000 \mathrm{rpm}$ for 30 minutes and, although this did not result in an immediate separation of the layers, the mixture was allowed to stand. After a period of 48 hours there was substantial separation of the layers, with the upper layer containing the recovered oil. This upper layer was washed with methanol and the base oil recovered in $75 \%$ yield (based on a $90 \%$ base oil content in the waste lubricant oil), whilst the lower layer, containing TESAC and additives, was treated with water to recover the ionic liquid that was heated above $50{ }^{\circ} \mathrm{C}$ to re-form TESA for re-use in a closed loop recovery system. The 
ATR-FTIR spectra along with thermal, moisture content, trace element analysis density and viscosity measurements were used to compare the recovered oil with pure base oil samples.

\subsubsection{The $\mathbf{P}_{6,6,6,14} \mathrm{Cl}$ recovery process}

The solubility of the base oil in the ionic liquid $\mathrm{P}_{6,6,6,14} \mathrm{Cl}$ offers an alternative methodology for recovery of base oil, with a potential advantage over TESAC, in that the liquid state of $\mathrm{P}_{6,6,6,14} \mathrm{Cl}$, at room temperature, has a lower viscosity $(0.70 \mathrm{~Pa}-\mathrm{s})$ and a higher thermal stability than TESAC [Blasucci et al., 2009]. The potential of this IL for recovery of the base oil was studied using a real waste lubricant oil system only.

Real waste lubricant oil system: A mixture of $\mathrm{P}_{6,6,6,14} \mathrm{Cl}(10.7 \mathrm{~g})$ and of the filtered waste GM10W40 multi-grade semi-synthetic lubricant oil (10.7g) was heated at $80{ }^{\circ} \mathrm{C}$ for $30-45$ minutes and centrifuged at $8000 \mathrm{rpm}$ for 30 minutes at room temperature. The mixture was allowed to settle for a period of up to 24 hours, after which a clear separation into two layers was achieved. The upper layer, which was a solution of the base oil in the IL, was decanted off and washed with methanol to separate off the base oil as a distinct layer from the methanol-IL layer. The IL was recovered from the methanol-IL layer by evaporating off the methanol to give $\mathrm{P}_{6,6,6,14} \mathrm{Cl}$ that can be reused in a closed-loop system The upper base oil layer was rotary evaporated to remove traces of methanol and was recovered as a viscous liquid in $56 \%$ yield. The ATR-FTIR spectra along with thermal, moisture content, trace element analysis density and viscosity measurements were used to compare the recovered oil with pure base oil samples. 


\subsection{Characterisation of Recovered Oil Samples and Ionic Liquids}

The recovered oils from the ionic liquid processes were characterised by comparison with pure base oil samples using ATR-FTIR spectra, moisture content, trace element analysis, and density and viscosity data. The ILs recovered for reuse and recycle were characterised by their FTIR spectra.

ATR-FTIR spectra were obtained using a Perkin Elmer Spectrum 100 FTIR spectrometer with a Universal ATR sampling-accessory and Dynascan interferometer, analysing within the $4000-$ $400 \mathrm{~cm}^{-1}$ range with 100 scans at a $4 \mathrm{~cm}^{-1}$ resolution. Moisture content was measured with TitroLine Karl Fischer equipment; and viscosity, density and viscosity index measurements were determined using the ASTM 7042 (ASTM, 2014) method in an Anton Paar SVM 3000/G2 Stabinger viscometer. $\mathrm{C}$ and $\mathrm{H}$ contents were determined by standard procedures and trace elemental analyses were obtained by Inductively Coupled Plasma-Optical Emission Spectroscopy (ICPOES) using a Perkin Elmer Optima 7300DV with an argon carrier gas, and by X-ray Florescence (XRF) using an energy dispersive Bruker S4 Explorer XRF spectrometer. The XRF and ICP-OES spectrometers were calibrated using a reference hydrocarbon sample (Standard base oil 20). Recovered oil samples were acid-digested prior to elemental analysis in an Anton Paar multiwave 3000 microwave oven using $9 \mathrm{ml} \mathrm{HNO}_{3}, 0.5 \mathrm{ml} \mathrm{HCl}$ and $2 \mathrm{ml} \mathrm{H}_{2} \mathrm{O}_{2}$ per $0.8 \mathrm{~g}$ of recovered oil sample. Digested samples were filtered through a $0.45 \mu \mathrm{m}$ cellulose nitrate membrane filter and analysed for elemental content using a modified EPA 3052 (EPA, 1996) method. 
The physical properties of the recovered base oil samples are compared in Table 3 with data on the reference oils, SN150, commercial (virgin) GM10W-40 lubricant oil and with those on the waste GM10W-40 lubricant oils studied. Comparison of the trace elemental analyses of the recovered base oils with the same reference and waste oils is in Table 4.

\begin{tabular}{|c|c|c|c|c|c|c|}
\hline \multirow{2}{*}{ Materials } & \multirow{2}{*}{$\begin{array}{c}\text { Appearan } \\
\text { ce }\end{array}$} & \multirow{2}{*}{$\begin{array}{c}\text { Moisture } \\
\text { content } \\
\text { (ppm) }\end{array}$} & \multirow{2}{*}{$\begin{array}{l}\text { Density } \\
\text { at } 15^{\circ} \mathrm{C} \\
\left(\mathrm{g} / \mathrm{cm}^{3}\right)\end{array}$} & \multicolumn{2}{|c|}{$\begin{array}{c}\text { Kinematic } \\
\text { viscosity }\left(\mathrm{mm}^{2} / \mathrm{s}\right)\end{array}$} & \multirow{2}{*}{$\begin{array}{l}\text { Viscosit } \\
y \text { index }\end{array}$} \\
\hline & & & & $40^{\circ} \mathrm{C}$ & $100^{\circ} \mathrm{C}$ & \\
\hline SN150 & $\begin{array}{c}\text { Pale } \\
\text { yellow }\end{array}$ & 70.4 & 0.880 & 31.4 & 5.2 & 94.2 \\
\hline $\begin{array}{c}\text { Commercial GM10W-40 } \\
\text { lubricant oil }\end{array}$ & $\begin{array}{c}\text { Pale } \\
\text { yellow }\end{array}$ & 742.3 & 0.871 & 92.9 & 13.8 & 150.6 \\
\hline $\begin{array}{c}\text { Waste GM10W-40 } \\
\text { lubricant oil }\end{array}$ & Black & 1400.6 & 0.879 & 98.9 & 14.0 & 144.7 \\
\hline $\begin{array}{l}\text { Recovered base oil from } \\
\text { TESA/TESAC process }\end{array}$ & Brown & 388.0 & 0.869 & 97.2 & 14.6 & 156.6 \\
\hline $\begin{array}{l}\text { Recovered base oil from } \\
\mathbf{P}_{6,6,6,14} \mathrm{Cl} \text { process }\end{array}$ & Brown & 759.6 & 0.867 & 146.2 & 19.7 & 155.0 \\
\hline
\end{tabular}

Table 3 Physical properties of recovered base oils compared with reference materials

\section{Results \& Discussion}

\subsection{Solubility of waste oil components in ionic liquids}

The relative solubilities of the components of waste lubricant oils (Table 2) show that the reference base oil, SN150, is insoluble in the polar ionic liquids - BMIMCl, $\mathrm{SMIMHSO}_{4}, \mathrm{HBetNTf}_{2}$ and $\mathrm{HMIMBr}$ - at room temperature and $80^{\circ} \mathrm{C}$. The key types of additive are also insoluble at room temperature in these ionic liquids although some of them become soluble at $80^{\circ} \mathrm{C}$. The ionic liquid 
$\mathrm{P}_{6,6,6,14} \mathrm{Cl}$ which contains a long chain hydrophobic hydrocarbon cation that dominates its structure enabling it to dissolve the base oil at room temperature and $80{ }^{\circ} \mathrm{C}$. Some of the key additives are, however, also soluble in this ionic liquid particularly at $80{ }^{\circ} \mathrm{C}$. All of the key components of waste lubricant base oils are soluble in TESA, the precursor of the ionic liquid TESAC at room temperature but the base oil is not soluble in TESAC at this temperature.

\begin{tabular}{|c|c|c|c|c|}
\hline Elements & $\begin{array}{c}\text { Commercial } \\
\text { GM10W-40 } \\
\text { lubricant oil } \\
\quad\left(\mathrm{mgl}^{-1}\right)\end{array}$ & $\begin{array}{c}\text { Waste } \\
\text { GM10W-40 } \\
\text { lubricant oil } \\
\quad\left(\mathrm{mgl}^{-1}\right)\end{array}$ & $\begin{array}{c}\text { Recovered base oil from } \\
\text { TESA/TESAC process } \\
\left(\mathrm{mgl}^{-1}\right)\end{array}$ & $\begin{array}{l}\text { Recovered base oil } \\
\text { from } \mathbf{P}_{6,6,6,14} \mathrm{Cl} \\
\text { process }\left(\mathrm{mgl}^{-1}\right)\end{array}$ \\
\hline $\mathbf{F e}$ & 2.1 & 2.5 & 2.5 & 2.6 \\
\hline $\mathbf{N i}$ & 1.5 & 3.1 & 3.1 & 3.1 \\
\hline $\mathbf{Z n}$ & 5.1 & 8.6 & 2.5 & 5.2 \\
\hline $\mathbf{P b}$ & 2.3 & 2.3 & 2.3 & 2.3 \\
\hline $\mathbf{N a}$ & 0.6 & 1.1 & 0.6 & 1.0 \\
\hline Mg & 2.2 & 3.8 & 2.1 & 2.3 \\
\hline $\mathrm{Cr}$ & 2.8 & 2.8 & 2.8 & 2.8 \\
\hline Cd & 4.6 & 4.7 & 3.3 & 4.6 \\
\hline Al & 0.1 & 0.1 & 0.1 & 0.1 \\
\hline $\mathbf{B a}$ & 2.9 & 3.0 & 2.9 & 3.0 \\
\hline Mn & 4.1 & 4.2 & 4.2 & 4.2 \\
\hline $\mathrm{Cu}$ & 1.2 & 1.2 & 1.2 & 1.3 \\
\hline Co & 2.4 & 2.4 & 2.4 & 2.4 \\
\hline
\end{tabular}

Table 4 Elemental analysis of recovered base oils compared with virgin and waste GM10W-40 lubricant oils

On the basis of these data the ionic liquid solvents, TESAC and $\mathrm{P}_{6,6,6,14} \mathrm{Cl}$, offer potential for use in the selective separation and recovery of the base oil from waste lubricant oils (Table $5)$. 


\begin{tabular}{|c|c|c|c|}
\hline Elements & $\begin{array}{c}\text { Waste GM10W-40 } \\
\text { lubricant oil }\end{array}$ & $\begin{array}{c}\text { Recovered base oil } \\
\text { from TESAC/TESA } \\
\text { process }\end{array}$ & $\begin{array}{c}\text { Recovered base oil } \\
\text { from } \mathbf{P}_{6,6,6,14} \mathbf{C l} \\
\text { process }\end{array}$ \\
\hline $\mathrm{C}+\mathrm{H}$ & 98.9 & 99.0 & 99.0 \\
\hline $\mathrm{S}$ & 0.466 & 0.278 & 0.285 \\
\hline $\mathrm{Si}$ & $n d$ & 0.575 & $n d$ \\
\hline $\mathrm{As}$ & $n d$ & $n d$ & 0.334 \\
\hline $\mathrm{Ca}$ & 0.371 & 0.067 & 0.174 \\
\hline $\mathrm{P}$ & 0.131 & 0.028 & 0.229 \\
\hline $\mathrm{Cl}$ & $n d$ & $n d$ & \\
\hline
\end{tabular}

Table 5 Bulk carbon and hydrogen and trace element analysis of recovered base oils compared with waste GM10W-40 lubricant oil (expressed as \% by weight)

\subsection{Development of low temperature ionic liquid systems for the recovery of base oils from waste lubricant oils}

Two low temperature processes for the recovery of base oils from waste lubricant oils using ionic liquids were developed from studies on model and real waste lubricant oils - the TESA/TESAC and $\mathrm{P}_{6,6,6,14} \mathrm{Cl}$ processes. The TESA/TESAC process exploits the insolubility of base oils in the ionic liquid TESAC which is prepared in situ from the solvent TESA in which base oils are soluble while the $\mathrm{P}_{6,6,6,14} \mathrm{Cl}$ process is based on the direct solubility of base oils in this ionic liquid.

The recovered oils from the ionic liquid processes were characterised by comparison with pure base oil samples using ATR-FTIR spectra, moisture content, trace element analysis, and density 
and viscosity data. The ATR-FTIR spectra for the recovered base oil from both processes (Figures 1a and 1b) were found to be in good agreement with the reference base oil,

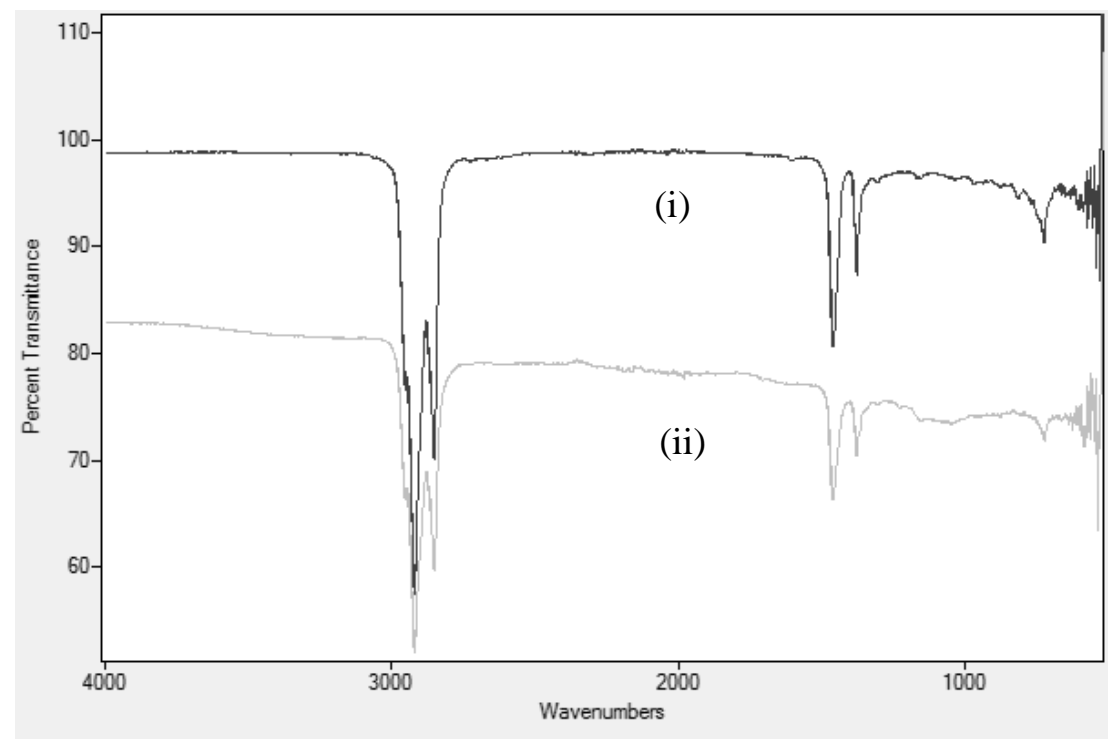

(a)

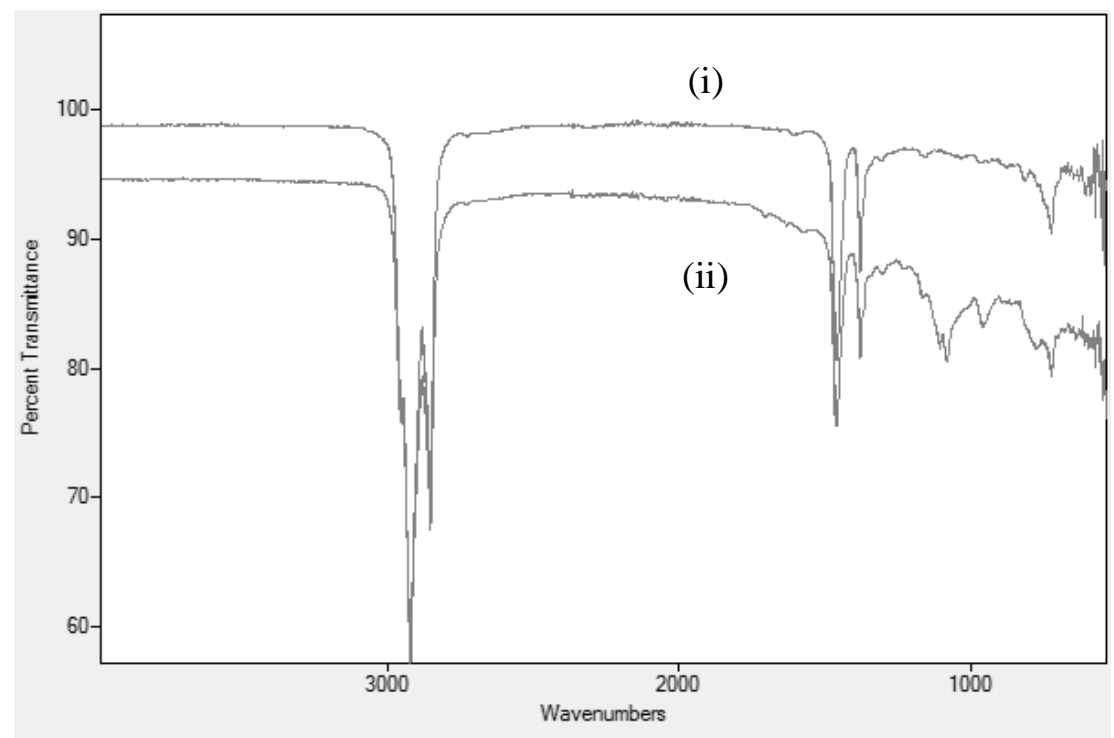

(b)

Figure 1. (a) ATR-FTIR spectra of (i) reference base oil (SN150) and (ii) recovered base oil from $\mathrm{P}_{6,6,6,14} \mathrm{Cl}$ process, and (b) ATR-FTIR spectra of (i) reference base oil (SN150) and (ii) recovered base oil from TESA/TESAC process 
The physical properties of the recovered base oil samples from both processes are compared in Table 3 with those of (i) a pure base oil SN150, (ii) a commercial lubricant oil GM10W-40 and (iii) a sample of used GM10W-40 oil. The moisture contents in the recovered base oil samples are much lower than that in the waste GM10W-40 lubricant oil but are comparable with that of the commercial lubricant oil. The densities of the recovered base oil samples are similar to those of the reference oils GM10W-40 and SN150. The recovered oil samples also have high viscosity indices, typical of Group V (synthetic) base oils, in line with that of the commercial GM10W-40 but higher than that of SN150. Generally, a high viscosity index indicates small viscosity changes with temperature with a high viscosity index being advantageous in engine lubricants because the oil is thin enough to flow easily at low temperature (which is critical in cold starts), yet is viscous enough to function at high temperature.

The chemical analyses of the recovered oils have total $\mathrm{C}+\mathrm{H}$ contents of $>99$ wt.\% with small amounts of $\mathrm{S}, \mathrm{Ca}$ and $\mathrm{P}$ that are less than the $0.47,0.37$ and $0.13 \%$ respectively found in the used GM10W-40 oil - the S, Ca and P contents for the base oil recovered in the TESA/TESAC process, for example are $0.28,0.07$ and $0.03 \%$ respectively. The oil recovered from the $\mathrm{P}_{6,6,6,14} \mathrm{Cl}$ did, however, also contain $0.33 \% \mathrm{Cl}$ arising from the IL. The trace metal contents in the recovered oil from the used GM10W-40 oil (Table 4) are low and similar to those found in the commercial GM10W-40 oil sample.

The ATR-FTIR spectra (Figures $2 \mathrm{a}$ and $2 \mathrm{~b}$ ) for the recovered IL from each process TESA/TESAC and $\mathrm{P}_{6,6,6,14} \mathrm{Cl}$ - were found to be in good agreement with the reference spectra for 
the respective ILs, showing that the ionic liquid can be recovered for recycle and reuse in the process.

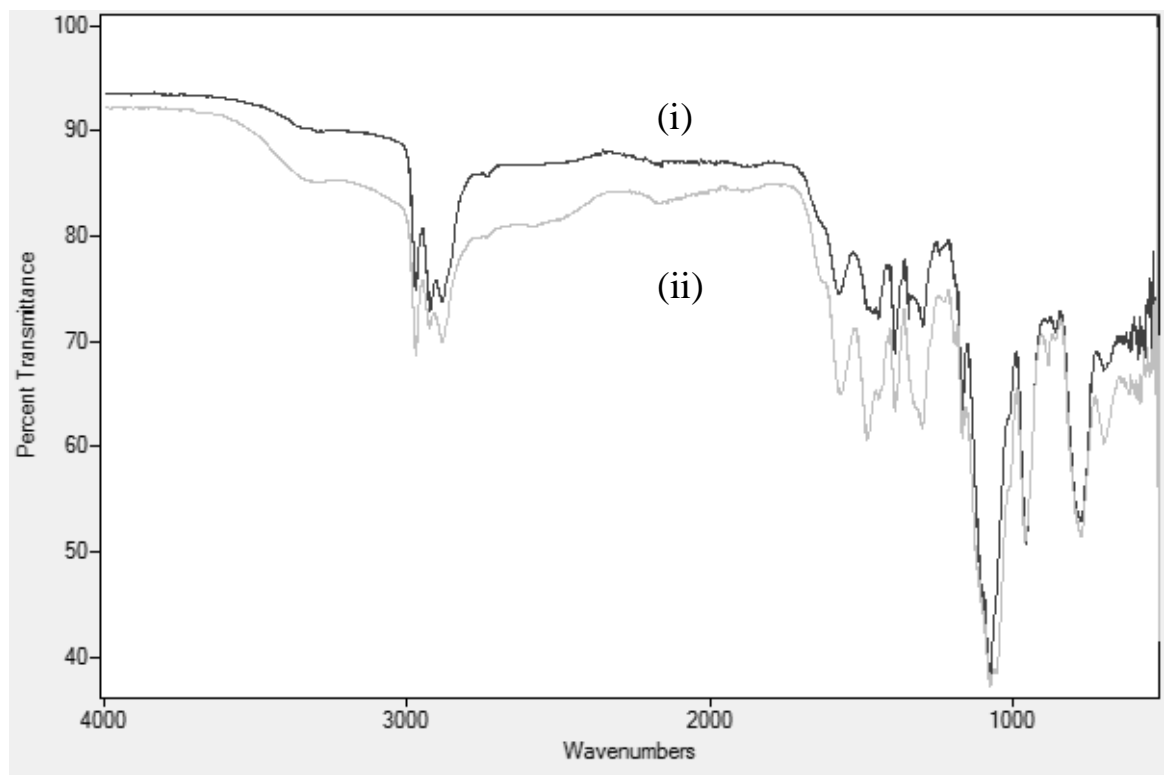

(a)

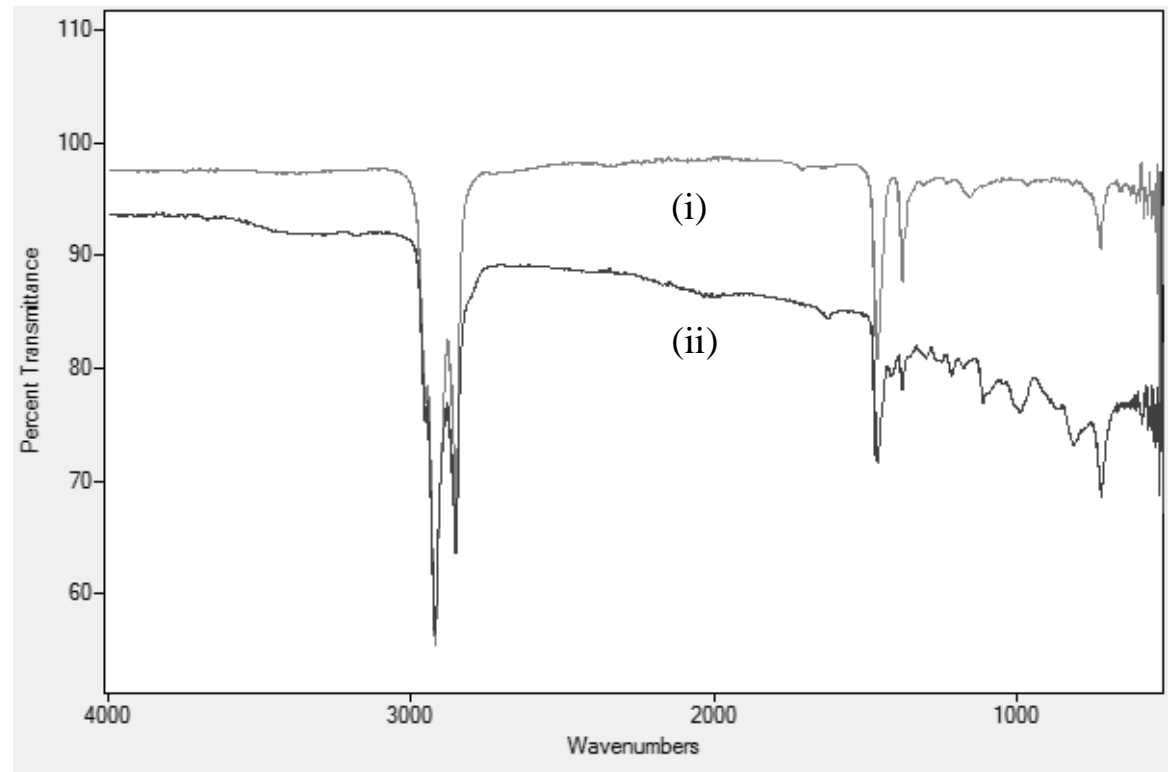

(b)

Figure 2. (a) ATR-FTIR spectra of (i) recovered IL from the TESAC process and (ii) reference IL, TESAC and (b) ATR-FTIR spectra of (i) recovered IL from the $\mathrm{P}_{6,6,6,14} \mathrm{Cl}$ process and (ii) reference $\mathrm{IL}, \mathrm{P}_{6,6,6,14 \mathrm{Cl}}$ 
Ionic liquid methodologies have been developed for the management of waste lubricant oils to recover the value in the base oils from this high tonnage waste stream. The recovery processes are carried out at low temperatures and are enviromentally friendly alternatives to the use of volatile organic solvents and adsorption methods. Two ionic liquid processes for re-refining waste lubricant oils are reported: one based on an ionic liquid in which the waste lubricant base oil is insoluble in the ionic liquid (TESAC), and one in which the waste lubricant base oil is soluble in the ionic liquid $\left(\mathrm{P}_{6,6,6,14} \mathrm{Cl}\right)$.

In the total TESA/TESAC process shown in the flow diagram (Figure 3) the waste lubricant oil, comprising the base oil and most of the performance additives, is dissolved in the solvent TESA which is converted in situ by reaction with carbon dioxide to the ionic liquid TESAC in which the base oil is insoluble. The base oil is separated off as a distinct layer and can be easily recovered. The TESAC at the end of the process as shown in Figure 3 can also be recovered for potential reuse in the process or converted to TESA for reuse, by heating the recovered IL above $50^{\circ} \mathrm{C}$. Typically ionic liquids can be recycled up to 5 times with no loss of extraction efficiency.

In the total $\mathrm{P}_{6,6,6,14} \mathrm{Cl}$ process shown in the flow diagram (Figure 4), the base oil is separated from most of the additives and other impurities as a solution in the ionic liquid from which the recovered base oil can be extracted easily by treatment with methanol. Similarly to the TESA/TESAC process, the $\mathrm{IL}_{6,6,6,14} \mathrm{Cl}$, in this system, as shown in Figure 4, can be recovered for reuse and recycle, minimising reagent use. 


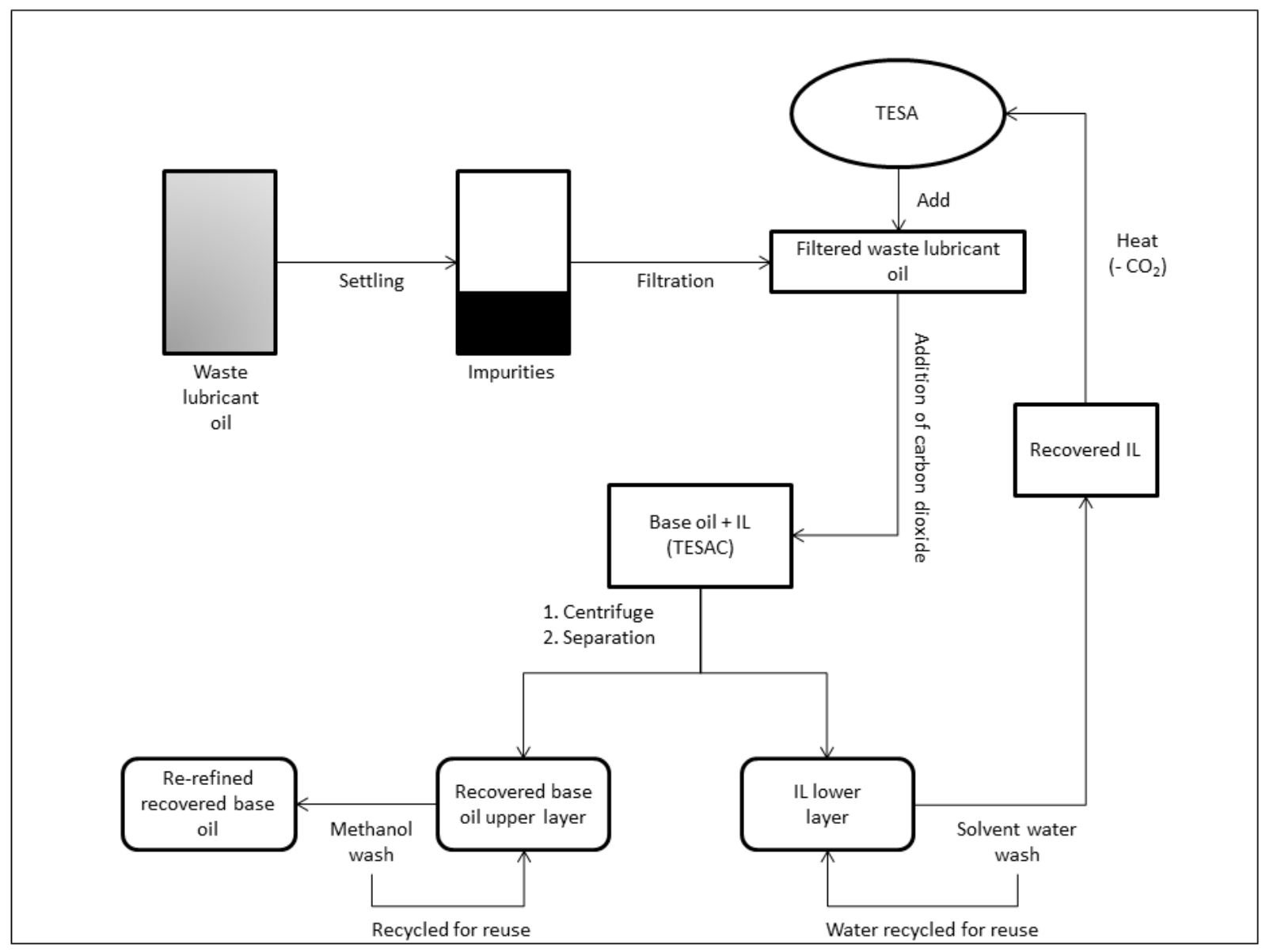

Figure 3. Schematic diagram of base oil recovery by the TESA/TESAC process

The recovered base oils from both of the novel, low-temperature ionic liquid processes TESA/TESAC and $\mathrm{P}_{6,6,6,14} \mathrm{Cl}$ - have properties consistent with lubricant oils in commercial use and have the potential to be returned to the commercial cycle. The higher base oil recovery yields in the TESA/TESAC process and the disadvantage of the presence of traces of chlorine in oil recovered in the $\mathrm{P}_{6,6,6,14} \mathrm{Cl}$ process make the TESA/TESAC method the favoured process. 


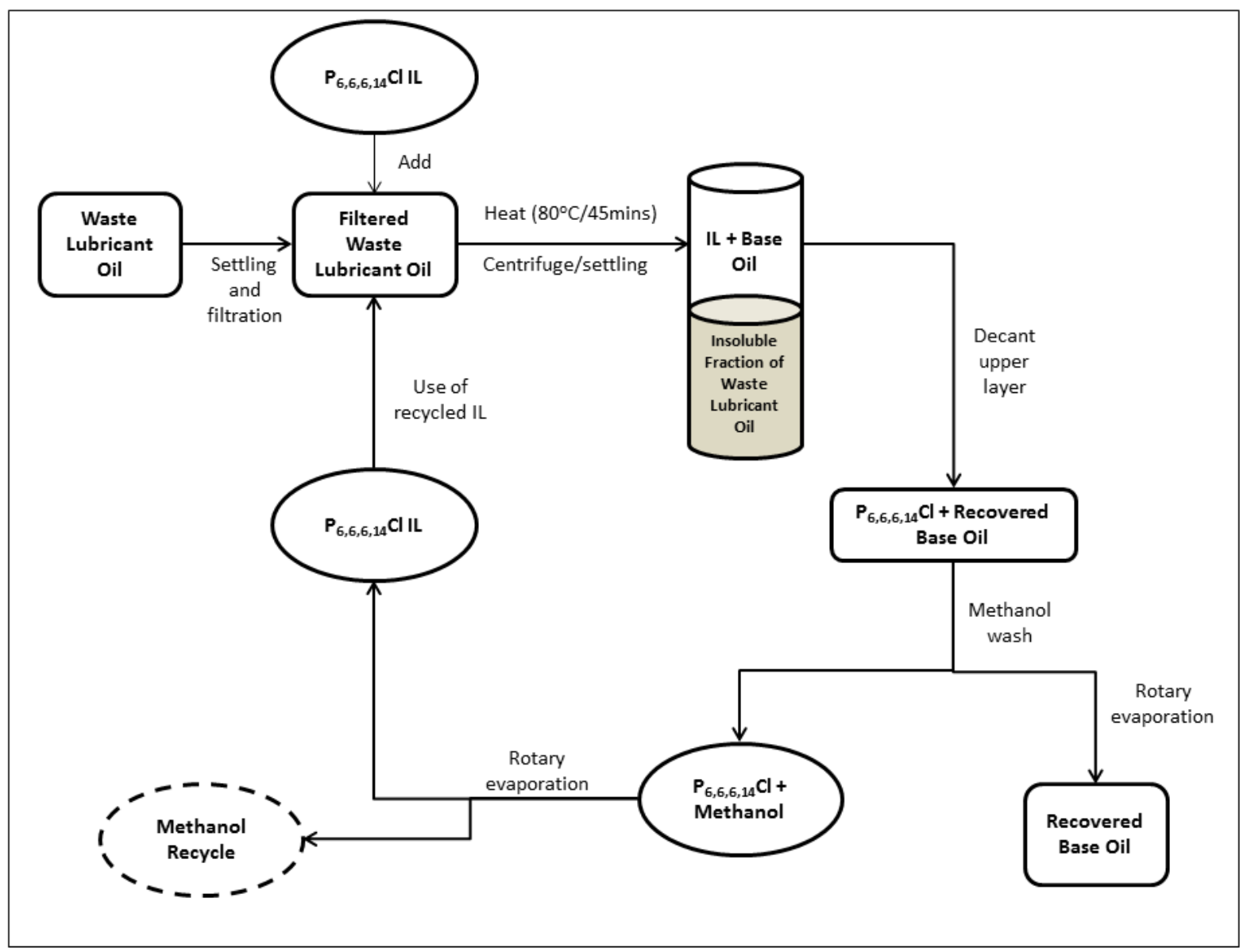

Figure 4. Schematic diagram of base oil recovery by the $\mathrm{P}_{6,6,6,14} \mathrm{Cl}$ process

\section{Conclusion}

Waste lubricant oils are classified as hazardous waste that can be managed by recovery for reuse and recycle, hydrocracking to produce fuels, incineration with energy recovery and less satisfactorily by direct incineration or disposal at a hazardous waste site. Hydrocracking and incineration give rise to only one second use for the waste oil, but recovery for recycle provides the opportunity to achieve multiple reuse stages for recycled oils and should, with the use of suitable technologies, be the preferred management option. The percentage of waste lubricating oils returned to the commercial cycle in Europe, for example, is less than $50 \%$ but there are 
opportunities to improve the percentage recycled. Many types of separation stages have been established for the recovery of waste lubricant oils in re-refining processes including: adsorption processes such as those based on acid-clay treatment; on distillation; and on the use of volatile organic extractants. Most of these processes, however, involve steps that make use of high temperatures, adsorbents that have to be disposed of as hazardous materials or volatile organic solvents all of which adversely affect their economic and/or environmental suitability.

The processes described here for the management of waste lubricating oils offer two novel lowenergy ionic liquid-based methodologies that have been developed to recover base oils of sufficient quality for reuse as lubricant oils from waste oils as well as the opportunity to recover the ionic liquids, for recycle and reuse, within the systems thereby minimising reagent use and providing a route to closed-loop recovery and recycle. One process uses 3-(triethoxysilyl)-propylammonium3-(triethoxysilyl)-propyl carbamate (TESAC), in which the waste lubricant base oil is insoluble, and the other uses trihexyltetradecylphosphonium chloride $\left(\mathrm{P}_{6,6,6,14} \mathrm{Cl}\right)$ in which the base oil is soluble. In the TESA/TESAC process waste oil components, including the base oil, are dissolved in the solvent 3-aminopropyl-triethoxysilane (TESA) which is converted, in situ, with carbon dioxide to TESAC, recovering the base oil as an insoluble layer. In the $\mathrm{P}_{6,6,6,14} \mathrm{Cl}$ process the base oil is separated as a solution in the ionic liquid from which it can be extracted with methanol. The recovered oils from both processes have properties consistent with lubricant oils in commercial use. In most circumstances the TESA/TESAC process will be preferred because it achieves a higher yield of recovered base oil and because of the presence of $\mathrm{Cl}$ in $\mathrm{P}_{6,6,6,14} \mathrm{Cl}$. 


\section{Acknowledgements}

We acknowledge the financial support (to FT) from the Lagos State Government, Nigeria to undertake this research work and the Royal Academy of Engineering for provision of funds for equipment.

\section{REFERENCES}

ASTM (2014) D 7042-14 Standard test method for dynamic viscosity and density of liquids by Stabinger Viscometer (and the calculation of kinematic viscosity, ASTM International West Conshohocken PA, USA

Blasucci, V.M.; Dilek, C.; Huttenhower, H.; John, E.; Llopis-Mestre, V.; Pollet, P.; Eckert, C.A.; Liotta, C.L. (2009) One-component, switchable ionic liquids derived from siloxylated amines Chem. Commun., 1, 116-118.

Cull, S.G,; Holbrey, J.D.; Vargas-Mora, V.; Seddon, K.R,; Lye, G.J. (2000) Room temperature ionic liquids as replacements for organic solvents in multiphase bioprocess operations. Biotechnol. Bioeng. 69(2), 227-233.

Elbashir, N.O.; Al-Zahrani, S.M.; Abdul Mutalib, M.I.; Abasaeed, A.E. (2002) A method of predicting effective solvent extraction parameters for recycling of used lubricating oils Chem.Eng. Process. 41(9) 765-769.

Emam, E.A.; Shoaib, A.M. (2012) Re-refining of used Lube Oil, II - by Solvent/Clay and Acid/Clay-Percolation Processes. ARPN J. Sci.Technol. 2, 1034-1041.

EPA(1996) SW-846 test method 3052: microwave assisted acid digestion of siliceous and organically based matrices. EPA Washington, DC, USA 
Europeam Commission (2014) Commision Decision of 18 December 2014 amending Decision 2000/532/EC on the list of waste pursuant to Directive 2008/98/EC of the European Parliament and the Council Text with EEA relevance - Official Journal of the European Commission L370/44. Fuentes, M.J.; Font, R.; Gomez-Rico, M.F.; Martin-Gullon, I. (2007), Pyrolysis and Combustion of waste lubricant oil from diesel cars: decomposition and pollutants, J. Anal. Appl. Pyrolysis 79(1-2), 215-226

Hamad, A.; Al-Zubaidy, E.; Fayed, M.E. (2005) Used lubricating oil recycling using hydrocarbon solvents. J. Environ. Manag. 74(2), 153-159.

Hsu, Y.L.; Liu C.C; (2011) Evaluation and selection of waste lubricating oil technology, Envir. Monit. Assess., 176(1-4) 197-212.

Hsu, Y.L.; Lee, C.H.; Kreng, C.H. (2010) The application of Fuzzy Delphi Method and Fuzzy AHP in lubricant regenerative technology selection Expert Syst. Appl., 37, 419-425

Jafari, A.J.; Hassanpour, M. (2015) Analysis and comparison of lubricants, regenerative technologies in the world. Resour. Conserv. Recycl. 103, 179-191.

Kamal, A.; Khan, F. (2009) Effect of extraction and adsorption on re-refining of used lubricant oil. Oil Gas Sci. Technol. - Revue d'Institut Francais du Petrole (IFP) 64(2), 191-197.

Kanokkantapong, V.; Kiatkittipong, W.; Panyapinyopol, B.; Wongsuchoto, P.; Pavasant, P. (2009) Used lubricating oil management options based on life cycle thinking. Resour. Conserv. Recycl. 53(5), 294-299.

Khowatimy, F.A.; Priastamo, Y.; Febriyanti, E.; Riyantoko, H.; Trisunaryanti, W. (2014) Proc.Environ. Sci., 20, 225-234. 
Lateef, H.; Grimes, S.M.; Morton, R.; Mehta, L. (2008) Extraction of components of composite materials: ionic liquids in the extraction of flame retardants from plastics. J.Chem.Technol.Biotcechnol. 83(4), 541-545.

Lateef, H.; Grimes, S.M.; Kewcharoenwong, P.; Bailey, E. (2009) Ionic liquids in the selective recovery of fat from composite foodstuffs J.Chem.Technol.Biotcechnol. 84(11), 1681-1687.

Lateef, H.; Grimes, S.M.; Kewcharoenwong, P.; Feinberg, B. (2009) Separation and recovery of cellulose and lignin using ionic liquids: a process for recovery from paper-based waste. J.Chem.Technol.Biotcechnol. 84(12), 1818-1827.

Lateef, H.; Gooding, A.; Grimes, S.M. (2012) Use of 1-hexyl-3-methylimidazolium bromide ionic liquid in the recovery of lactic acid from wine. J.Chem.Technol.Biotcechnol. 87(8), 1066-1073. Lea-Langton, A.; Giannakeas, N.; Rickett, G.L.; Dupont, V. (2010) Waste Lubricating oil as a source of hydrogen fuel using chemical looping steam reforming. SAE Int. J. Fuel Lubricants $\mathbf{3 ( 2 )}$, $810-818$.

Liu, Y.; Cheng, J.; Shen, W.; Song, Y. (2005) Regeneration of used lubricating oils by supercritical fluid extraction Petrol. Sci. Technol 23(7-8), 909-14.

Lukic, J.; Orlovic, A.; Spiteller, M.; Jovanovic, J.; Skala, D. (2006) Re-refining of waste mineral insulating oil by extraction with N-methyl-2-pyrrolidone. Separ. Purif. Technol. 51(2), 150-156. Martins, J.P. (1997) The extraction-flocculation re-refining lubricating oil process using ternary organic solvents. Ind. Eng. Chem. Res. 36(9), 3854-3858.

Mohammed, R.R.; Ibrahim, I.A.R.; Taha, A.H.; Mckay, G. (2013) Waste lubricating oil treatment by extraction and adsorption Chem.Eng. J. 220, 343-351. 
Nockemann, P.; Thijs, B.; Pittois, S.; Thoen, J.; Glorieux, C.; Van Hecke, K.; Van Meervelt, L.; Kirchner, B.; Binnemans, K.; (2006) Task-specific ionic liquid for solubilizing metal oxides. J. Phys. Chem. B 110(42), 20978-20992.

Pawlak, Z.; Urbaniak, W.; Kaldonski, T.; Styp-Rekowski, M. (2010) Energy conservation through recycling of used oil. Ecol. Eng., 36(12), 1761-1764.

Pereiro, A.B.; Rodríguez, A. (2010) An ionic liquid proposed as solvent in aromatic hydrocarbon separation by liquid extraction. AIChE J. 56(2), 381-386.

Rogers, R.D.; Voth, G.A. (2007) Ionic liquids. Acc.Chem.Res. 40(11), 1077-1078.

Tripathi, A.K.; Ojha, D.K.; Vinu, R. (2015) Selective production of valuable hydrocarbons from waste motorbike oil via catalytic fast pyrolysis using zeolites J. Anal. Appl. Pyrolysis, 114, 281292.

Welton, T. (1999) Room temperature ionic liquids. Solvents for synthesis and catalysis. Chem.Rev. 99(8), 2071-2084.

Wilkes, J.S. (2002) A short history of ionic liquids from molten salts to neoteric solvents. Green Chem. 4(2) 73-80. 